\title{
Diante das limitações linguísticas de um paciente afásico: a interlocutora-terapeuta como conarradora
}

\author{
Livia Miranda Oliveira* \\ Layanne Ferreira dos Santos Carmo**
}

\begin{abstract}
Resumo
O estudo aqui apresentado é informado teórica e metodologicamente pelo arcabouço da Sociolinguística Interacional e tem como objetivo investigar a participação da interlocutora-terapeuta na construção da história de AVE de um paciente afásico por meio de um olhar para as ações da interlocutora que penetram o turno a turno da narração. Os dados analisados foram gerados em vídeo, através do método de entrevista em profundidade, e transcritos de acordo com convenções dos analistas da conversa com algumas adaptações de autoras da área da interação. As análises qualitativas de cunho interpretativista nos permitiram observar que as ações da terapeuta contribuíram para o desenho/formatação da narrativa, para sustentação dos footings operantes na interação em curso e para a manutenção da intersubjetividade. Tais ações se configuraram como cooperativas e motivadoras, além de terem possibilitado o engajamento ativo do paciente na narração.
\end{abstract}

Palavras-chave: Interação. Narrativa. Afasia.

\section{Introdução}

No cenário das interações sociais, o conteúdo e a direção que as estruturas narrativas assumem são, conforme consideram Ochs e Capps (2001), contingências do input narrativo dos interlocutores, que fornecem, eliciam, criticam, refutam e esboçam inferências. A partir dessa concepção, as narrativas vão sendo coconstruídas pelos narradores primários e pelos interlocutores, configurando-se como uma realização interacional. Cabe destacar que os papéis assumidos pelos interlocutores (conarradores) e pelos narradores primários não são fixos, mas sim intercambiáveis, dado o caráter interacional dessa construção que se revela na dinamicidade dos footings assumidos pelos participantes.

* Universidade Federal de Sergipe (UFS).

** Universidade Federal de Sergipe (UFS). 
Alguns contextos interacionais favorecem sobremaneira a participação colaborativa do interlocutor na construção da narrativa, como é o caso do contexto de geração dos dados deste estudo, que consistiu em uma sessão terapêutica de fonoaudiologia em que o terapeuta conduzia a interação por meio do estabelecimento de tópicos e da apresentação de perguntas, mediando/orquestrando-a, bem como por meio da intervenção no desenvolvimento do tópico e no direcionamento do rumo da interação. Nessa sessão terapêutica, a fonoaudióloga utilizou o método de entrevista em profundidade (cf. BRITTEN, 2006) para coletar dados que possibilitassem a avaliação da linguagem do paciente e que compusessem o corpus da pesquisa por ela coordenada. Mishler (1999, p. 105) considera que "a presença do entrevistador como um coparticipante é um componente do discurso inevitável e essencial, e o modo de o entrevistador questionar influencia a produção de uma história".

Não obstante o contexto em que foram construídas, quando olhamos para as narrativas a partir de uma perspectiva que concebe tal construção como não exclusiva do narrador primário, mas que conta com a colaboração do interlocutorconarrador, identificamos nuances que revelam que a formatação turno a turno da narrativa é uma contingência interacional (OLIVEIRA, 2013). Acerca das atividades discursivas em meio às quais narrativas são construídas, Ochs e Capps (2001), em seus estudos sobre narrativas cotidianas, chamam nossa atenção para propriedades das conversas que se refletem nas histórias contadas no curso dessa atividade discursiva. São elas: (i) o caráter em aberto (open-ended) da conversa (i. e. o fluxo da fala está nas mãos dos interlocutores, sendo a conversa uma realização interacional que emerge de momento a momento); (ii) o meio comum de anunciar eventos não resolvidos (i. e. a interação conversacional realiza a função de tentar construir e reconstruir sentido das experiências de vida); e (iii) o envolvimento como marca de familiaridade (i.e. a conversa informal estabelece e mantém relacionamentos íntimos em muitas comunidades). Embora o contexto interacional dos estudos das autoras tenha sido situações conversacionais cotidianas, suas contribuições são extremamente valiosas para este estudo, visto que também nos interessa olhar para situações interacionais, embora menos ordinárias que as conversas, mas não menos interacionais.

Ochs e Capps (2001), ao olharem para histórias contadas em conversas cotidianas, destacam a penetração de ações ditas conversacionais, como, por exemplo, perguntas, clarificações, desafios e especulações. A exemplo das autoras, 
o objetivo deste estudo consiste em investigar a participação da interlocutoraterapeuta na construção da história de AVE de um paciente afásico por meio de um olhar para as ações da interlocutora que penetram o turno a turno da narração. Pretendemos, com isso, por um lado, buscar entender como as ações da interlocutora-terapeuta atuam na formatação da narrativa (i.e. o caráter das ações é colaborativo ou corretivo), e por outro lado, compreender algumas possibilidades de participação do fonoaudiólogo nesse empreendimento interacional que é a narração de uma história.

Uma vez que este estudo é informado teórica e metodologicamente pelo arcabouço da Sociolinguística Interacional (doravante SI), ele assume a concepção de linguagem como "um sistema simbólico social e culturalmente construído, usado de forma que reflete significados sociais em um nível macro (identidade do grupo, diferenças de status) e cria significados sociais em um nível micro (i. e., o que alguém está dizendo e fazendo em um dado momento no tempo)" (SCHIFFRIN, 1994, p. 102). Essa visão de linguagem, por sua vez, encontra fundamentos no modelo interacional de comunicação, cuja proposta será apresentada na seção que segue aquela em que abordaremos as afasias e alguns aspectos de interações que envolvem pessoas com afasia. Subsidiados pelos fundamentos desse modelo de comunicação, cabe-nos adentrar a cena interacional, se temos a pretensão de investigar o que ali se passa, e, para isso, um caminho consiste em investigar os papéis dos participantes na interação, que podem ser alcançados por meio de um olhar para os footings por eles assumidos. Na seção 3, dissertaremos sobre a noção de footing, inaugurada por Erving Goffman. Por fim, na seção 4, apresentaremos a visão de narrativa com a qual lidaremos neste estudo, que consiste na visão de narrativa como uma construção social, cultural e interacional.

\section{Interações face a face com pessoas com afasia}

A afasia é clássica e tradicionalmente definida como um distúrbio de linguagem decorrente de lesão cerebral adquirida em virtude de Acidente Vascular Encefálico, tumor, traumatismo cranioencefálico entre outras afecções neurológicas. Embora essa definição possa ser aplicada a todos os casos de afasia, não há como especificar/predeterminar um padrão de fala para cada tipo dessa patologia, uma vez que ela se manifesta de modo peculiar em cada caso, dependendo sobretudo do local e da extensão da lesão, bem como do tipo de acidente vascular (isquêmico 
ou hemorrágico). Segundo Coudry (2008, p. 32), "para além da lesão cerebral, um sujeito é afásico quando lhe faltam recursos de produção e interpretação para exercer a linguagem".

Encontramos no discurso de pessoas com afasia diferentes estratégias de adaptação à lesão (cf. WILKINSON et al., 2010, 2007; PENN, 1987; GOLDSTEIN, 1939, 1948; JACKSON, 1931), que funcionam como recursos alterativos de significação (cf. COUDRY, 2008), ou seja, que consistem no modo que elas encontraram para construir sentidos, para se fazerem entender, diante das limitações linguísticas que apresentam. $\mathrm{O}$ modo que o afásico encontra para se comunicar com o outro desenha a singularidade do seu discurso. Há casos, por exemplo, em que essas pessoas utilizam discurso reportado direto como uma estratégia de simplificação que lhes possibilita dizer aquilo que, sem o uso dessa construção, seria impossível (cf. OLIVEIRA; OLIVEIRA, 2014), como também, há casos em que essas pessoas se valem da prosódia como índice de posse da palavra (cf. LANINI; OLIVEIRA; VIEIRA, 2010).

Torna-se relevante destacar que, mesmo interessados em compreender as construções discursivas de pessoas com afasia, conforme consideram Heeschen e Schegloff (2003), não podemos transformar seres humanos em meros usuários da língua por, presumidamente, pertencerem a um grupo que apresenta desordens da linguagem. Os autores destacam que, na vida cotidiana, podemos de fato ver quem, além de afásicos, são essas pessoas, ou melhor, quem ou o que elas estão sendo e como elas são o que são, e com isso compreender o que, em relação a uma pessoa com afasia de Broca, é afásico e o que não é.

A postura de buscar compreender o que pessoas com afasia conseguem fazer com (e através) da linguagem, em vez de investigar os déficits por elas apresentados (i.e. aquilo que elas não conseguem fazer por meio da linguagem), acaba por clamar aos estudiosos das afasias, sobretudo aos profissionais da área da saúde, a desviar um pouco o foco de interesse da patologia para a pessoa que a apresenta, voltando o olhar para seu discurso, para suas construções discursivas via uso da linguagem (OLIVEIRA, 2013). No que tange às narrativas, podemos considerar que as limitações linguísticas do afásico podem não impossibilitar as construções narrativas (em outras palavras, podem não afetar a competência narrativa) se não nos limitamos a olhar para a estrutura da língua e se tornamos relevante, nas investigações, a colaboração do outro na construção de narrativa, conforme propõe este artigo. 
Ao investigar situações interacionais que envolvem pessoas com afasia com acometimentos semelhantes ao do paciente deste estudo, vemos ratificada a tese de que a linguagem é uma forma de ação conjunta. Em muitas situações, essas pessoas não conseguem construir seus enunciados sozinhas ou, em outros momentos, constroem enunciados ininteligíveis que necessitam de reparo da parte do outro. Aqueles que interagem com pessoas com afasia necessitam ser mais tolerantes, concedendo a elas um tempo maior para produzirem seus enunciados, ou seja, devem maximizar os turnos do afásico, não obstante essa maximização de turnos esteja em contraste com as regras de organização da conversa com sua preferência por minimização de turnos (HEESCHEN; SCHEGLOFF, 2003).

Segundo Heeschen e Schegloff (1999), as pessoas que interagem com pessoas com afasia tendem a agir como terapeutas diante dos erros das mesmas, o que, segundo os autores, reforça o impedimento. Para eles, fornecer um modelo corretivo como uma possível ajuda para pessoas com afasia é o mesmo que tratá-las como debilitadas. Neste artigo, propomo-nos a investigar as ações do interlocutor de modo a alcançar o caráter dessa ação (corretivo ou colaborativo) e poder traçar algumas considerações acerca do papel do terapeuta em casos de afasia.

Goodwin (1995) demonstra que, em interações com afásicos, quando os interlocutores coordenam seus papéis de participação de forma particular e atentam para a sequência dos eventos interacionais, eles podem conjuntamente superar as limitações impostas pelo vocabulário repetitivo e severamente reduzido do participante.

Em sua pesquisa sobre narrativa de afásicos, Oliveira (2013) observou que a fala afásica, com suas limitações linguísticas, impostas por um comprometimento da linguagem decorrente de lesão cerebral adquirida, não impossibilitou a atuação dos afásicos como narradores e seu engajamento ativo em construções discursivas (de sentido, princípios, valores, posturas, identidades, etc.) no curso da narração, e que a colaboração do outro enquanto conarrador foi extremamente significativa para as construções alcançadas, para o sucesso da comunicação. Nesse sentido, atribuir coautoria à audiência consiste em reconhecer a necessidade de uma parceria para sustentação de uma interação (DURANTI, 1986). 


\section{Contribuições do modelo interacional de comunicação}

O modelo interacional de comunicação abarca os fundamentos necessários para melhor compreender a comunicação humana na interação. De acordo com a proposta de Schiffrin (1994), este modelo considera que a base da comunicação é o comportamento, seja ele intencional ou não, verbal ou não. A partir dessa visão, comportamentos como silêncio e direcionamento do olhar, informações físicas como suor e rubor, qualidades paralinguísticas de elocuções verbais, gestos, posturas e expressões faciais, entre outros, transmitem mensagem mesmo não sendo intencionais nem conscientes.

Assim sendo, a comunicação ocorre quando um indivíduo encontra-se em uma situação interacional, ou seja, quando seus comportamentos, intencionais ou não, estão disponíveis às observações do outro. No que diz respeito ao caráter intencional da informação transmitida por um comportamento, Goffman (1959 apud SCHIFFRIN,1994) argumenta que existem informações intencionais (information given) e não intencionais (information given-off). A primeira é aquela informação intencionalmente designada a ser percebida como comunicativa, ao passo que a segunda é aquela informação transmitida sem intenção de ser percebida como comunicativa (apud SCHIFFRIN, 1994). A esse respeito, Schiffrin (1994, p. 398) argumenta que "devido ao fato de qualquer dos dois tipos de informação poder ser interpretado por um interlocutor, qualquer dos dois tipos é comunicativo".

Ademais, esse modelo modifica a concepção tradicional de falante e ouvinte ao delegar ao ouvinte um papel muito mais ativo no processo de comunicação. Diante da informação advinda do falante, o ouvinte recorre ao seu conhecimento de mundo e realiza inferências que lhe possibilitam construir sentidos. Dessa forma, o sentido não viria encapsulado na mensagem, nos pensamentos do falante, e não seria de responsabilidade do falante/emissor (como no modelo do código), não seria fruto de inferências das intenções do falante (como no modelo inferencial), mas, sim, emergiria da interação entre (i) a informação intencional ou não intencionalmente emitida por um falante, (ii) a forma como a informação é situada e (iii) as interpretações que o ouvinte designa a essa informação (SCHIFFRIN, 1994).

Nesse modelo, portanto, tanto falante como ouvinte têm responsabilidade na construção do sentido, não sendo este de responsabilidade apenas do falante, como nos outros modelos, e estando atrelado ao contexto (i. e. o sentido depende 
de como a informação é situada). O ouvinte, assumindo um papel mais ativo no processo comunicativo, deverá encontrar sentido no comportamento situado do falante e tentar atribuir múltiplas interpretações (referencial, emotiva, social) a qualquer informação que se torne disponível (SCHIFFRIN, 1994).

Levando em conta que o ouvinte tem responsabilidade na construção do sentido (que não emana da mensagem e nem mesmo está na intenção do falante) daquilo que o falante pretendeu comunicar, mal-entendidos podem acontecer, o que nos possibilita argumentar que ocorre comunicação mesmo na ausência de entendimentos mútuos (WATZLAWICK, 1967 apud SCHIFFRIN, 1994).

A partir da perspectiva da Sociolinguística Interacional, uma informação só tem sentido se for interpretada no contexto, que abarca, além dos sinais emitidos pelo código, informações não intencionais como as pistas de contextualização (cf. GUMPERZ, 1982) que auxiliam na sinalização de pressuposições contextuais disparadoras de inferências, por sua vez, situadas. Para se alcançar as inferências (situadas) que permitem a construção de sentidos, o processo comunicativo também conta com informações advindas do ouvinte, como, por exemplo, seu conhecimento de mundo e seu estado psicológico.

De acordo com Schiffrin (1994, p. 402), "a proposta de que as pessoas utilizam pistas de contextualização para fazer inferência (para Gumperz, inferência situada) indica que a habilidade para contar com informação given-off é parte da capacidade cognitiva através da qual os interactantes interpretam o que está em curso". Além de sinalizar pressuposições contextuais e possibilitar inferências, as pistas de contextualização indicam mudanças de footing, noção que será melhor entendida na seção seguinte.

\section{Compreendendo o papel do outro por meio de um olhar para os footings da interação}

Em um dos seus estudos sobre interação social, Goffman (1979) introduz a noção de footing, que chama a atenção, entre outros, para os papéis de participação dos interactantes. $\mathrm{O}$ autor sugere que uma forma de capturar a sinalização do falante de seus status de participação na interação é através do footing. Essa noção representa o alinhamento, a postura, a posição, a projeção do "eu" de um participante na sua relação com o outro, consigo próprio e com o discurso em construção (RIBEIRO; GARCEZ, 2002). Os footings dos participantes são sinalizados na maneira como 
eles gerenciam a produção ou a recepção das elocuções. Goffman faz um reexame das noções clássicas de falante e ouvinte, abordando a complexidade das relações discursivas presentes na estrutura de produção (relativa ao falante) e na estrutura de participação (relativa ao ouvinte).

A começar pela noção de ouvinte, que Goffman (1979) substitui pela noção de estrutura de participação, e que está relacionada ao processo de examinar o que um falante diz e de acompanhar o essencial de suas observações, o autor nos chama a atenção para o fato de que nos encontros face a face podem estar presentes não apenas ouvintes ratificados, mas também, ouvintes não ratificados, que ele chama de "ouvinte intrometido" (escuta às escondidas) e de "ouvinte por acaso" (escuta sem intenção de ter escutado). Esses participantes eventuais são considerados por Goffman como "circunstantes". Por outro lado, os ouvintes oficiais, ou seja, os ouvintes ratificados, em um momento podem ser o interlocutor endereçado, e em outro, o interlocutor não endereçado, conforme coloca o autor. Além dessa tipificação, o autor nos apresenta possibilidades de relações entre falante, interlocutor endereçado e interlocutor não endereçado. São elas: jogo paralelo, que envolve um subgrupo de participantes ratificados; jogo cruzado, que ocorre entre participantes ratificados e circunstantes; e jogo colateral, que envolve os circunstantes.

Uma vez que nos interessamos pelo status de participação, ou seja, pela relação de um participante com uma dada elocução, vemo-nos obrigados a olhar para o cenário onde relações mais amplas se desenvolvem como a relação de todos os participantes com essa elocução, que se configura na "estrutura de participação" do momento de fala em que tal elocução foi proferida. Estamos alegando, portanto, que precisamos olhar para a "situação social", que, segundo Goffman (2002, p. 17), consiste em

\footnotetext{
"um ambiente que proporciona possibilidades mútuas de monitoramento, qualquer lugar em que um indivíduo se encontra acessível aos sentidos nus de todos os outros que estão 'presentes', e para quem os outros indivíduos são acessíveis de forma semelhante".
}

O autor argumenta que "a fala é socialmente organizada, não em termos de quem fala para quem em que língua, mas também como um pequeno sistema de ações face a face que são mutuamente ratificadas e ritualmente governadas, em suma, um encontro social" (p. 19). 
Voltando, agora, o foco para a noção de falante, para tratar dos formatos de produção, como sugere Goffman (1979), devemos ter em mente que o indivíduo engajado na posição de produzir elocuções pode ocupar os seguintes papéis: animador (quem profere o discurso), autor (quem produz o discurso) e responsável (quem motiva o discurso e dele se beneficia). Ao assumir qualquer um desses papéis, o falante se esforça para estabelecer um alinhamento recíproco da parte daqueles a quem essa tomada de posição é endereçada. Esse delineamento da estrutura de participação e do formato de produção, segundo o autor, fornece a base estrutural para a análise das mudanças de footing, uma vez que as mudanças de footing são constituídas e evidenciadas, em grande parte, através de mudanças na estrutura de participação da conversa. Como o próprio autor considera, processos discursivos induzem mudanças no footing.

Footings envolvem alinhamentos, os quais podem ser mantidos através de um trecho de comportamento que pode ser mais logo ou mais curto do que um enunciado. Em outras palavras, uma pessoa pode, por exemplo, manter um alinhamento após finalizar sua produção verbal ao manter sua orientação corporal (postura) e/ou seu direcionamento de olhar. De acordo com Goffman (2002, p. 113), "uma mudança de footing implica uma mudança no alinhamento que assumimos para nós mesmos e para os outros presentes, expressa na maneira como conduzimos a produção ou a recepção de uma elocução". Os participantes mudam constantemente seus footings ao longo de uma interação, sendo essas mudanças muito comumente vinculadas à linguagem, porém, quando este não for o caso, ao menos podemos afirmar que os marcadores paralinguísticos estarão presentes. Quando cedemos a palavra, assumindo, assim, o footing de interlocutor (endereçado ou não), fica-nos garantida a expectativa de reingresso no mesmo footing em que a deixamos. Os falantes se realinham (mudam de alinhamento) em uma conversa quando sentem necessidade de reajustar seu status de participação (GAVRUSEVA, 1995).

Segundo Duranti (1986), falantes e ouvintes são iguais não meramente porque seus papéis são intercambiáveis (eles podem não ser em algumas situações), mas porque todo ato de fala é dirigido a (e deve ser ratificado por) uma audiência. Ainda segundo o autor, em trocas verbais menos rotinizadas, como, por exemplo, contar histórias, a forma e o conteúdo da fala são continuamente reformatados/ remodelados pelos coparticipantes através de suas habilidades para criar certos alinhamentos e sugerir ou impor certas interpretações. 
Por meio da narração, o falante, através de gestos, da entonação, da seleção de palavras, da disposição dos eventos, propõe um certo alinhamento à história que está sendo contada. Entretanto, a audiência pode oferecer possibilidades de interpretação (do que está sendo narrado) e de alinhamento que diferem da proposta do falante, dado o caráter ativo conferido à participação da audiência em situações interacionais (GOODWIN, 1986, p. 283). Assim considerando, "o sentido da história emerge não apenas das ações do falante, mas, ao invés, como um produto de um processo interacional colaborativo em que a audiência exibe um papel extremamente ativo". Essa visão interacional de narrativa, que dá respaldo a este estudo, será tratada na seção a seguir.

Cabe ressaltar que os status de falante e ouvinte são desmembrados em diferentes status dependendo da atividade discursiva na qual falantes e ouvintes encontramse imersos, como, por exemplo, na atividade de narrar, em que falantes assumem o footing de narradores primários e ouvintes se alinham como conarradores. Nas palavras de Oliveira e Bastos (2012, p. 199) "quando se instaura um enquadre de narração, temos a seguinte configuração de footings: um participante da interação em curso se alinha como narrador e os demais se alinham como interlocutores da história e conarradores". Porém, conforme as próprias autoras colocam, "devese ter em conta que a projeção de uma dada atividade discursiva (narração) por uma das partes pode ter como resposta a adoção ou o abandono dos footings até então assumidos (narrador, ouvintes da história)". Desse modo, "os footings são interacionalmente contingentes, ao invés de pré-determinados, consistindo em categorias flutuantes na interação".

\section{Narrativa sob o prisma interacional}

Entre as diferentes disciplinas que se interessam por estudar narrativas, encontramos concepções bastante distintas acerca do que seria uma narrativa, de modo que tal definição assume o formato de uma problematização muitas vezes conflitante. Dentre os estudiosos que abraçam essa discussão, neste artigo, a voz de Riessman $(2008$, p. 4) se sobressai na defesa de que "narrativa está em todo lugar, mas nem tudo é narrativa". Conforme destaca a autora, no contexto contemporâneo, quando alguém fala ou escreve algumas linhas, o produto final é chamado de narrativa, visão esta que vai de encontro à sua tese de que "nem toda fala e texto é uma narrativa" (p. 5). 
Ao nos alinhamos à concepção da autora, cabe-nos definir, então, o que é uma narrativa (o que define um trecho de fala como uma narrativa), já que nem todo trecho de fala é uma narrativa, e, para isso, podemos optar por uma dentre as diversas definições que se espraiam nesse campo de estudo. No caso deste artigo, assumimos, em termos de definição, a concepção laboviana de que uma narrativa consiste em uma sequência de orações narrativas, com verbo no passado simples, ordenadas de modo a haver uma correspondência entre a sequência dessas orações e a sequência real dos eventos descritos nessas orações. A partir desse prisma, até mesmo uma sequência de duas orações narrativas conectadas por uma juntura temporal consiste em objeto de interesse. Assumir a concepção de Labov (1972) de narrativa não implica entender a narrativa exatamente conforme o tratamento do autor, ou seja, como um método de recapitulação de experiências passadas e como uma produção exclusiva do narrador. Portanto, sem negligenciar (ao contrário, assumindo) a visão de Labov acerca dos elementos que compõem uma narrativa, este estudo admite que narrar também é construir experiências, construir sentidos, não sendo tais construções exclusivas do narrador primário, mas, sim, construções que contam com a participação/colaboração do conarrador.

A ideia de coconstrução está na base de qualquer perspectiva interacional em linguagem ou discurso, sendo que o prefixo "co" pretende cobrir uma gama de processos interacionais, incluindo colaboração, cooperação e coordenação. Segundo Jacoby e Ochs (1995), a coconstrução se refere à "criação conjunta de uma forma, interpretação, atitude, ação, atividade, identidade, instituição, capacidade, ideologia, emoção ou outra realidade culturalmente significativa" (p. 171). Ainda segundo as autoras, "uma das mais importantes implicações de se tomar a posição de que tudo é coconstruído através da interação é que existe uma responsabilidade distribuída entre interlocutores para a criação de coerência sequencial, identidades, sentido e eventos" (p. 177).

Sob um prisma interacional (e também social e cultural), "a narrativa passa a ser vista como uma construção social e não mais uma representação do que aconteceu. Operam nessa construção o filtro afetivo que guia a lembrança, as especificidades da situação de comunicação em que a narrativa é contada, a ordem sociocultural mais ampla (BASTOS, 2004, p. 121).

Narrativas, então, são construções discursivas situadas em contextos interacionais que podem abarcar desde situações de entrevista, em que o entrevistador assume um papel de mero eliciador da história, gerando dinâmicas 
interpessoais assimétricas e carentes de intimidade, até situações conversacionais, que, em geral, primam pela espontaneidade das produções e tendem a reduzir assimetrias interacionais.

No arranjo interacional negociado para a narração, o narrador costuma ter a posse da palavra por um período maior que o interlocutor, que, por sua vez, exibe breves participações, não tendo, no entanto, que se manter em silêncio, mas podendo contribuir com a construção da história, ao menos, sinalizando entendimento e acompanhamento ( $i$. e. mínimos feedbacks). Os turnos do interlocutor, geralmente, são do tipo "mm" e "ahm ram", não quebrando o fluxo do relato (SACKS, 1992; BASTOS, 2005), ou então consistem em pedidos de esclarecimentos ou comentários, e até mesmo em reações por meio de expressões faciais, gestos ou interjeições, mostrando atenção à história (cf. OLIVEIRA; BASTOS, 2011). Conforme proposta deste artigo, serão investigadas as participações do interlocutor na história de AVC contada por um homem afásico.

Independentemente de os interlocutores estarem ou não fisicamente presentes, se participam verbalmente ou se estão em silêncio, eles (os interlocutores) exercem forte influência no que pode e deve ou não ser dito, bem como no modo como será dito. A partir da visão da interpretação como um processo local, situado, a dependência mútua entre as palavras do falante e as respostas do interlocutor é considerada o ponto de partida para qualquer empreendimento hermenêutico, uma vez que o sentido é tido como coletivamente construído (DURANTI, 1986). Desse modo, entra em jogo a intersubjetividade entre narrador e interlocutor, de modo que, se o narrador entende que um determinado sentido/conceito/conhecimento não é partilhado por seu interlocutor, torna-se relevante que ele forneça explicações que propiciem o alcance da intersubjetividade, que, por sua vez, irá sustentar a colaboração do interlocutor na construção da narrativa, já que narrativas não são expressões de uma única subjetividade, mas, sim, coconstruções (cf. RIESSMAN, 2008).

Por outro lado, os interlocutores fornecem provas e contrapontos, apresentam os detalhes que estão faltando, exibem emoções, demonstram alinhamentos e não alinhamentos com o narrador, o que ilumina o fato de que a narração dos eventos não é algo predeterminado, mas uma construção conjunta (do aqui e agora da interação) entre narrador e interlocutores, em que ambas as partes estão engajadas ativamente na construção da narrativa. Nesse sentido, de acordo com Duranti (1986, p. 242), 
quando nos voltamos para trocas verbais menos roteirizadas, como, por exemplo, contar histórias, descobrimos que a forma e o conteúdo da fala são continuamente reformatados/remodelados pelos coparticipantes, através de suas habilidades para criar certos alinhamentos e sugerir ou impor certas interpretações.

Acerca do trabalho conjunto de construção da narrativa, Norrick (2007) alega que

da mesma forma que o narrador trabalha para desenhar uma história apropriada à audiência e ao contexto local, a audiência impõe seu próprio desenho: interrompendo, corrigindo, co-narrando. Narrativa conversacional é sempre uma narração interacional, mais ou menos polifônica, mas necessariamente negociada entre os participantes. O ouvinte não está em um estado passivo, mas em um envolvimento ativo no processo de narração (p. 136-137).

$\mathrm{O}$ autor também destaca que tão logo os interlocutores são ratificados como conarradores, eles passam a ser coautores da história, ajudando a determinar a trajetória, a estrutura e o ponto da narrativa, através de perguntas, comentários entre outras ações. As respostas dos interlocutores, ademais, ressaltam a natureza da narração como um evento narrativo, um evento de fala com suas próprias normas características que governam a cena, o direito de participação, o conteúdo da mensagem, a forma da mensagem e as regras de interpretação (NORRICK, 2007).

Embora o autor se refira a narrativas conversacionais, em outros contextos interacionais que não se caracterizam como de conversas, como é o caso deste estudo, podemos encontrar a penetração dessas mesmas ações que formatam o turno a turno da narração (cf. OLIVEIRA, 2013), sobretudo porque narrativas geradas em situações de entrevista semelhantes à deste estudo não são menos interacionais que narrativas conversacionais. Quando o cerne da questão está nas implicações do contexto interacional na formatação/construção da narrativa, não importando se o que se passa na interação é uma conversa ou uma entrevista, os estudos de narrativa conversacionais têm muito a contribuir.

Dentre os diversos estudos sobre narrativa, é notório o reconhecimento e a aplicabilidade no campo científico daqueles trabalhos que ocupam lugar de destaque na contemporaneidade, cujos autores se afiliam a uma vertente interdisciplinar que conjuga, sobretudo, contribuições advindas da antropologia e de uma linguística interacional no entendimento da atividade narrativa, esboçando uma interface entre perspectivas culturais e interacionais. 


\section{Aspectos metodológicos}

Este artigo é fruto de um projeto de pesquisa aprovado pelo Comitê de Ética em Pesquisa da Universidade Federal de Sergipe, intitulado Narrativa como instrumento de investigação clínica das afasias, o qual vem sendo desenvolvido desde 2013 na clínica escola de fonoaudiologia e compõe a linha Intervenção fonoaudiológica com adultos e idosos, que faz parte do grupo de pesquisa Intervenção fonoaudiológica e interdisciplinar nos diferentes ciclos da vida.

No início da execução do projeto acima referido, todos os pacientes com diagnóstico fonoaudiológico de afasia foram incluídos na pesquisa e receberam o Termo de Consentimento Livre e Esclarecido, que foi lido em voz alta pelo terapeuta e acompanhado pelo paciente ao final de uma sessão de atendimento clínico. Após a leitura do TCLE, foram feitos esclarecimentos aos pacientes de acordo com as dúvidas por eles apresentadas, e os pacientes levaram o documento para uma releitura atenta em casa, retornando com este assinado no próximo atendimento. No TCLE desta pesquisa constam informações (claras e precisas) sobre a participação voluntária dos pacientes, os objetivos da pesquisa, as metas previstas, os procedimentos que serão adotados, o sigilo da identidade dos pacientes, a ausência de custos de parte dos pacientes para participação na pesquisa, a possibilidade de retirada do consentimento ou interrupção da participação a qualquer momento, o acesso aos resultados da pesquisa pelos pacientes, entre outras informações afins. Mediante a confirmação das participações dos pacientes na pesquisa por meio da assinatura dos termos, teve início a geração dos dados. Os dois únicos critérios de exclusão consistem na não assinatura do TCLE e na presença de mutismo; todavia, todos os pacientes assinaram o termo e nenhum apresenta quadro clínico de mutismo.

Conforme estabelecido no TCLE, os encontros para a coleta de dados foram gravados em vídeo, de modo a possibilitar a captação de aspectos verbais e não verbais envolvidos na narração. Para uma posterior análise, os dados coletados foram transcritos de acordo com as convenções de transcrição desenvolvidas por Gail Jefferson, que se encontram em Sacks, Schegloff e Jefferson (2005), com adaptações sugeridas por Schiffrin (1987), para marcação de pausas, e Tannen (1989), para marcação do discurso reportado (cf. anexo).

Ageração de dados foi realizada através do método de entrevista em profundidade, em que foram apresentadas aos pacientes perguntas eliciadoras de narrativa. Tais perguntas foram do tipo open-ended (cf. RIESSMAN, 2008), demandando como resposta um relato/narração/história. 
Segundo Carrasco (1999), a entrevista, ao ser introduzida na clínica fonoaudiológica, ressignificou-se, favorecendo a emergência de aspectos subjetivos da linguagem do sujeito. No que tange à entrevista em profundidade, temos que consiste em um método menos estruturado, que busca detalhamento das informações concedidas pelo entrevistado por meio de perguntas adicionais baseadas no que a pessoa entrevistada disse, consistindo, principalmente, em esclarecimentos e busca de detalhes.

Uma vez que se trata de um estudo qualitativo, não há a pretensão de quantificar (mensurar) a linguagem dos participantes, nem mesmo de tipificar patologias, mas sim a intenção de analisar, com um olhar interpretativista, a fala em interação no cenário de uma consulta fonoaudiológica da qual participam um paciente afásico e uma terapeuta. Assim sendo, não será aplicado nenhum tratamento estatístico aos dados. A tarefa analítica será identificar e analisar as ações da interlocutora no curso da narração de uma história, ancorando-se em uma visão de narrativa como uma construção conjunta, resultado de um trabalho interacional entre narrador primário e narradores secundários (conarradores) (RIESSMAN, 2008; OCHS; CAPPS, 2001).

$O$ contexto institucional de geração dos dados consiste em uma consulta fonoaudiológica. $\mathrm{O}$ dia em que foi realizada a entrevista aqui analisada consistiu no primeiro dia de atendimento dos pacientes após as férias e o primeiro dia de contato dos alunos com seus novos pacientes. A terapeuta que realizou a entrevista já conhecia o paciente, pois acompanhava seu atendimento desde 2013. Diante da necessidade de repensar o planejamento terapêutico para o semestre que se iniciava, foi realizada uma reavaliação da linguagem por meio da entrevista que eliciou a narrativa sob análise.

\section{Análise}

A narrativa a ser analisada consiste na história de AVE de um paciente que apresenta afasia, cujo pseudônimo é Clóvis, construída durante uma sessão fonoaudiológica em que a terapeuta presente se chama Lívia. Em decorrência do AVE, além do comprometimento linguístico, Clóvis adquiriu uma hemiplegia de dimídio direito, que acarretou em afastamento da sua função laboral de mecânico e, posteriormente, em aposentadoria. Houve, com isso, uma alteração na dinâmica de suas relações socais, sendo que Clóvis, aos poucos, foi se isolando do convívio social. 
A terapeuta, conforme mencionado anteriormente, utilizou o método de entrevista em profundidade para geração de dados que se constituiriam em material linguístico para avaliação clínica da linguagem do paciente. Torna-se relevante destacar que não havia um protocolo predeterminado para a realização da entrevista, tendo sido utilizada apenas uma pergunta inicial estimuladora da narração com a finalidade de eliciar uma narrativa que se constituiria em material para análise linguística. As demais perguntas realizadas pela terapeuta emergiram no turno a turno da narração por contingências interacionais, não tendo sido, portanto, definidas a priori. A narrativa será apresentada abaixo em recortes que respeitam sua sequencialidade.

\begin{tabular}{|l|l|l|}
\hline 01 & Lívia & fique à vontade, [tá $\uparrow$ pro senhor me contar sua história $=$ \\
\hline 02 & Clóvis & {$[$ arram.] } \\
\hline 03 & Lívia & $=$ do derrame. como é, como foi $\downarrow(0.4)<$ o derrame do senhor $>(0.3)$ \\
\hline 04 & Clóvis & o derrame, $>$ o derrame $<$ foi quan: quando, quando eu ta: quando- \\
\hline 05 & & eu tava normal né $\uparrow$ quando eu tava normal, foi no: foi domin: \\
\hline 06 & & foi no domingo ( . ) uma:: umas seis horas, né $\downarrow$ tava deitado, \\
\hline 07 & & tava deitado, aí quando deitei assim umas seis horas da tarde, \\
\hline
\end{tabular}

$\mathrm{Na}$ linha 3, Lívia elicia a narrativa através de uma open-ended question (como foi?), que abre um espaço para Clóvis contar sua história sobre o AVE que o acometeu. A opção por utilizar o termo derrame em substituição a AVE na pergunta eliciadora se deve ao desconhecimento da parte de Clóvis acerca da sigla e da expressão Acidente Vascular Encefálico. Podemos considerar que Lívia, por meio de sua ação (convite à narração), projeta o footing de narrador para Clóvis, que se alinha como tal na linha 4 ao iniciar sua história por meio de uma orientação (nos termos de Labov) do ouvinte/interlocutor acerca do dia, do horário, dos personagens e do local em que teve início a sua história de AVE.

Devido às manifestações, no discurso oral, do distúrbio da linguagem de 
Clóvis, como perseverações, digressões e sobretudo anomia, a inteligibilidade de seu discurso é comprometida, o que afeta, à primeira vista, o entendimento de sua narrativa pelo outro. Portanto, ao longo das análises, as orações narrativas (ON) serão isoladas para melhor visualização dos dados; todavia, elas serão apresentadas inicialmente no contexto discursivo de sua ocorrência, conforme pode ser observado nos trechos abaixo, que apresentam a transcrição na íntegra.

No excerto abaixo será apresentado o início da narração propriamente dita.

\begin{tabular}{|c|c|c|}
\hline 08 & Clóvis & aí, quando quando deitei assim, aí::>ligeirinho ligeirinho $<$,né $\uparrow$ \\
\hline 09 & & aí, a cabeça cabeça ficou ( (passa a mão na cabeça) ) - quando \\
\hline 10 & & eu sai::, quando eu sai:: aí:, minha minha mulher e minhas \\
\hline 11 & & 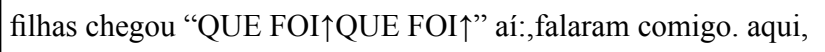 \\
\hline 12 & & $($ ( mostra o braço direito) ) aí, ela disse "QUE FOI $\uparrow$ ” aí oi esse \\
\hline 13 & & lado já tava, já tava assim. só aqui, né $\uparrow$ aqui tava normal. \\
\hline 14 & & aqui tava normal. ( (mostra o braço direito) ) só assim ( . ) no \\
\hline 15 & & domingo. aí, quando ela, "o que foi?? aí.( . ) falei com elas. \\
\hline 16 & & quando foi umas sete horas da noite, aí ela chegou e:: ">vamo, \\
\hline 17 & & vamo $<$ vamo comer pra:: o café" eu " > vamo, vamo $<$ " aí ta:: tava \\
\hline 18 & & assim, aí(.) ela me deu, ela me deu a:: o café os (negócios \\
\hline 19 & & do café) assim, né $\uparrow$ aí quando eu botei aqui, quando botei \\
\hline 20 & & assim: aí caiu. aí quando caiu, quando caiu assim ( . ) o café. \\
\hline 21 & & aí caiu assim, ela disse "eita $\uparrow$ foi:: foi ( 0.2$)$ foi o derrame."= \\
\hline
\end{tabular}

No trecho acima, as manifestações discursivas da sintomatologia afásica, como as (i) inúmeras repetições, (ii) os diversos autorreparos, (iii) os alongamentos frequentes, as interrupções abruptas e as pausas que sugerem anomias, (iv) os circunlóquios, que, no discurso de pessoas que não apresentam afasia podem estar presentes não tão frequentemente quanto no discurso de afásicos, comprometem a inteligibilidade da história. Tais manifestações ocasionam uma desorganização 
sintática dos enunciados, que pode ser fruto da dificuldade de seleção lexical (cf. PACHECO; PINTO, 2010), uma vez que o narrador primário apresenta afasia. Para facilitar a visualização das construções que de fato são o foco de interesse deste estudo, ao longo das análises, tais manifestações patológicas serão subtraídas em um procedimento de limpeza dos dados.

Nesse primeiro excerto da narrativa, o narrador primário apresenta o início do episódio de AVE pelo qual passou em sua casa, em um domingo, às seis horas da tarde, por meio de uma sequência de 16 (dezesseis) orações narrativas (ON) que se estendem da linha 2 à linha 30 (ON 1: deitei; ON 2: cabeça ficou ( ) ); ON 3: eu saí;

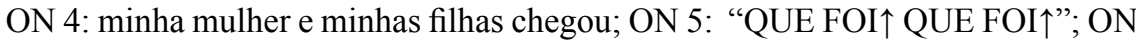
6: falaram comigo; ON 7: eu fiz assim ((mostra o braço direito)); ON 8: ela disse

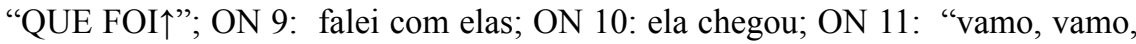
vamo comer"; ON 12: eu "vamo, vamo"; ON 13: ela me deu o café (os negócios do café); ON 14: eu botei aqui; ON 15: caiu; ON 16: ela disse "eita"). Conforme pode ser observado, a ON 5 pode ser parafraseada por minha mulher e minha filha me perguntaram o que estava acontecendo, a ON 11 pode ser parafraseada por ela me chamou para comer e a $\mathrm{ON} 12$ pode ser parafraseada por eu disse vamos. O uso do discurso reportado direto por afásicos é entendido como uma estratégia de adaptação ao déficit linguístico (OLIVEIRA; OLIVEIRA, 2014; OLIVEIRA, 2011; PENN, 1987).

Por meio de orações narrativas, o narrador primário relata que sentiu algo na cabeça quando estava deitado e que, quando foi tomar café, a convite da sua mulher e da sua filha, os utensílios do café (aos quais ele se refere por "negócios do café") caíram da sua mão e alguém que estava presente à mesa proferiu um comentário

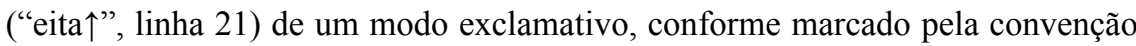
de transcrição de subida entonacional $(\uparrow)$. Ao proferir "ela disse, "eita $\uparrow$ ", na linha 21, o narrador não especifica o sujeito, que, com base na organização sequencial da história, poderia ser sua esposa ou sua filha. Na linha seguinte (22), Lívia se coloca no papel de conarradora e realiza uma solicitação de clarificação, como veremos no trecho da narrativa que será apresentado abaixo. Tal ação promove uma expansão da narrativa, que, de acordo com as últimas orações da linha 21 ("ela disse "eita $\uparrow "$ "; "foi o derrame"), já havia sido finalizada . 


\begin{tabular}{|c|c|c|}
\hline 21 & & aí caiu assim, ela disse "eita $\uparrow$ foi:: foi $(0.2)$ foi o derrame."= \\
\hline 22 & Lívia & $=$ a mulher do senhor? \\
\hline 23 & Clóvis & sim. aí quando: quando eu peguei assim, pra pegar o café, \\
\hline 24 & & caiu. quando caiu,( )então. foi:: foi o derrame. \\
\hline 25 & Lívia & e aí?= \\
\hline 26 & Clóvis & $=$ aí ela correu e chamou um:: cole: colega meu $>$ tinha, tinha $<$ \\
\hline 27 & & tinha um carro. aí:: (.) ela disse, " $>\underline{\text { vamos, }}$ vamos $<\uparrow$ ( ) \\
\hline 28 & & leve logo ele $\uparrow "$ aí:(.)aí quando eu vi já tava assim $\downarrow$ (0.2) num \\
\hline 29 & & sabia mais de nada, pelo amor de deus $\downarrow$ (.) mas só aqui $\uparrow$ só \\
\hline 30 & & esse [pedaço aqui $\uparrow]$ \\
\hline 31 & Lívia & [mas o senhor] estava vendo tudo $\downarrow$ \\
\hline 32 & Clóvis & hã?= \\
\hline 33 & Lívia & $=$ o senhor estava vendo tudo $\downarrow$ \\
\hline 34 & Clóvis & é. mas (num) pa:: pa: perguntar. pra perguntar, eu nu:m, num \\
\hline 35 & & sabia, né? \\
\hline 36 & Lívia & urrum. \\
\hline 37 & Clóvis & aí:: aí minha mulher chegou e: e no: (0.3) no(.) nes:tor \\
\hline 38 & & piva, nestor piva,né $\downarrow$ \\
\hline 39 & Lívia & urrum. \\
\hline
\end{tabular}

Podemos considerar que, por um lado, esse movimento de Lívia sustenta Clóvis no papel de narrador, e por outro, ele se interessa em continuar ocupando esse papel, pois ele não apenas responde à pergunta de Lívia na linha 23 (em outras palavras, realiza a clarificação), como também acrescenta informações 
explicativas à narrativa (em outras palavras, acrescenta uma explicação). Essa configuração do arranjo interacional com Clóvis e Lívia assumindo os footings de narrador primário e conarrador é mantida no decorrer da interação por meio de um trabalho interacional da parte de Lívia, interessada em conhecer com detalhes a história de Clóvis, e de Clóvis, interessado em contar seu drama.

Conforme podemos observar, após Clóvis, na linha 24, apresentar novamente o final da sua história, Lívia, na linha seguinte (25), ao proferir uma conjunção com entonação ascendente (e aí $\uparrow$ ), ou seja, ao realizar uma pergunta, apresenta uma proposta de expansão da narrativa, já que o uso conjunção implica continuidade da narração, acréscimo de outras orações narrativas. Essa ação de Lívia não ratifica a mudança de footing proposta por Clóvis ao finalizar sua narrativa na linha 24, sinalizando que ela (Lívia) deseja permanecer no mesmo footing (conarradora), o que requer de Clóvis um alinhamento recíproco que o faz permanecer no footing de narrador primário. De acordo com Ochs e Capps (2001), perguntas são ações conversacionais que penetram narrativas contadas em contextos interacionais.

Em suma, por um lado, Clóvis finaliza sua história, e, por outro, Lívia não considera a última oração narrativa apresentada por Clóvis como o fim da história, ou seja, ela não considera que a história chegou ao fim e solicita informações adicionais (e aí?). Podemos entender a ação de Lívia como uma identificação da ausência de um ponto (cf. LABOV, 1972) na narrativa de Clóvis, pois, do modo como está (do modo como está formatada até a linha 21), a narrativa de fato carece de razão de ser.

$\mathrm{Na}$ linha 26, vemos que Clóvis se apoia no discurso do interlocutor, repetindo a conjunção apresentada por Lívia, e aceita o convite de expansão, dando continuidade à narração propriamente dita por meio do acréscimo de outras orações narrativas nas linhas 26-30 (ON. 17: ela correu; ON 18: chamou um colega meu; ON. 19: ela disse "vamo, vamo, leve logo ele"). Entretanto, conforme vimos, Clóvis acrescenta apenas três orações narrativas, e, logo em seguida, apresenta uma nova proposta de finalização (aí quando vi já estava assim, não sabia mais de nada) e uma tentativa de abdicar do footing de narrador, que não é ratificada por Lívia no turno seguinte. Ela (Lívia), na linha 31, novamente, sinaliza que a narrativa de Clóvis carece de informações adicionais ao realizar o que Ochs e Capps (2001) chamam de especulação, um outro tipo de ação conversacional que penetra esse tipo de narrativa (narrativas interacionais): "mas o senhor estava vendo tudo $\uparrow "$ Essa solicitação de detalhes não provoca a continuidade da narração da parte de 
Clóvis, que parece interpretar a ação de Lívia como uma proposta de mudança do frame de narração para o de conversa, pois a única ação que ele realiza no turno seguinte consiste na resposta à especulação de Lívia, não dando continuidade à narração.

No turno seguinte à resposta de Clóvis, linha 36, Lívia profere "urrum", com alongamento de vogal, sinalizando tanto entendimento como resposta de acompanhamento (cf. BASTOS, 2005). O enunciado de Clóvis no turno seguinte, linha 37-38, sinaliza que ele entendeu a ação de Lívia de não ratificação da mudança de frame, pois ele não abandonou o footing de narrador e dá continuidade à narração por meio de uma nova oração narrativa (ON. 20: minha mulher chegou no nestor piva). Lívia, por sua vez, no footing de conarradora, prossegue sinalizando acompanhamento da história (linha 39: urrum), mostrando seu interesse na continuidade da narração. As orações narrativas que seguem tal sinalização e que se encontram no trecho abaixo serão destacadas no corpo da análise.

\begin{tabular}{|l|l|l|}
\hline 40 & Clóvis & quando cheguei lá, o rapaz disse, “não $\uparrow$ foi derrame, foi? \\
\hline 41 & & “fo::i.” não, leve ele pra joão alves” $\downarrow$ aí me levaram pra o \\
\hline 42 & & joão Alves.(.) quando cheguei lá no joão alves,(.)- passei a \\
\hline 43 & & noite toda lá(0.3)quando foi na segun::, na segun::da umas \\
\hline 44 & nove horas, o médico disse, “pode:: pode ir embora $\downarrow$ ” tava tudo \\
\hline 45 & & normal. só esse lado ((mostra perna e braço direito)) que tava \\
\hline 46 & & assim.(0.2) aí, peguei e vim embora, aí, quando peguei o \\
\hline 47 & ônibus $\downarrow$ a gente viemos,(.) aí a gente: a gente, a gente foi \\
\hline 48 & & comer, umas do:: do: doze horas eu comi, aí ela disse, \\
\hline 49 & & “deite um pouquinho” aí quando deitou $\downarrow$ começou de novo, assim \\
\hline 50 & & ói ((fica batendo a mão no coração)) ” acho que vou morrer $\uparrow=$ \\
\hline
\end{tabular}

A história do AVE de Clóvis, que, com base na primeira proposta de abandono do footing de narrador, teria finalizado em sua casa, estendeu-se, a partir da motivação (ou incentivo) e da contribuição da conarradora, para o hospital, 
conforme verificado nas seguintes orações narrativas: ON. 21: cheguei lá; ON. 22: o rapaz disse, "não foi derrame. foi $\uparrow$ leve ele pro joão alves.; ON. 23: me levaram para o joão Alves.; ON. 24: passei a noite toda lá; ON. 25: o médico disse, "pode ir embora"; ON. 26: peguei e vim embora; ON. 27: peguei o ônibus; ON. 28: a gente viemos; ON. 29: a gente foi comer; ON. 30: eu comi; ON. 31: ela disse, "deite um pouquinho"; ON. 32: começou de novo; ON. 33: "ói.tô assim, acho que vou morrer".

A continuidade e a finalização da narrativa serão apresentadas a seguir.

\begin{tabular}{|c|c|c|}
\hline 51 & Lívia & $=$ mas como é que estava a fala do senhor? \\
\hline 52 & Clóvis & hã $\uparrow$ \\
\hline 53 & Lívia & o senhor estava falando ainda $\downarrow$ \\
\hline 54 & Clóvis & (2.3) $>$ quando, quando $<$ ela falava comigo $\downarrow$, falava comigo $\downarrow$, \\
\hline 55 & & falava comigo assim, falava assim: devagarzinho. falando \\
\hline 56 & & comigo, né $\downarrow$-aí quando foi umas: umas duas horas, aí, pegaram \\
\hline 57 & & o:: carro, a gente foi lá no nestor piva.(.) quando foi no \\
\hline 58 & & nestor piva, aí o:: rapaz chegou e:: olhou e disse, "não $\uparrow$ ele \\
\hline 59 & & tem que:: passar, pelo menos uns cin: cinco dias lá no nestor \\
\hline 60 & & Piva"(0.8) aí(0.6) ficaram, ficaram lá nestor piva. lá, passei \\
\hline 61 & & $(0.4)$, passei lá, ele perguntando “diga seu nome $\uparrow$ "( 0.3$)$ “meu \\
\hline 62 & & nome é::, meu nome é clóvis joão da silva ramos.(0.8)"tá \\
\hline 63 & & bom $\downarrow "(0.6)$ aí(0.4)passou um dia, dois dias,(1.2)aí quando \\
\hline 64 & & perguntou de novo, dois dia ele perguntou, me deu o remédio de \\
\hline 65 & & dois, $(0.4)$ de dois $>$ como é? $<$ como o remédio- uma hora. duas \\
\hline 66 & & horas. eles vinha(.) daqui a pouco eles- no outro dia, ele:: \\
\hline 67 & & “diga seu nome”, aí pronto $\downarrow$ aí já, já. “diga seu nome $\uparrow ”$ “meu \\
\hline 68 & & nome $\downarrow$ (.) clóvis $\uparrow "$ aí (depois o resto), aí parou. parou. \\
\hline
\end{tabular}




\begin{tabular}{|l|l|l|}
\hline 69 & Lívia & isso foi nesses cinco dias que o senhor ficou lá? \\
\hline 70 & Clóvis & foi $\downarrow$ aí pronto. aí(.) eu já:: já: não sabia mais $\downarrow$ me chamavam, \\
\hline 71 & & e num sabia, num sabia dizer o nome $\downarrow>0$ meu nome<, < tudo>(.) \\
\hline 72 & & aí quando foi depois, daqui a pouco aí: eu tava, tava no \\
\hline 73 & & nestor piva(.) aí pronto quando mandaram ir embora pronto $\uparrow$ já \\
\hline 74 & & não sabia quem era, não sabia quem era $\downarrow$ o meu médico lá já \\
\hline 75 & & coisou $\downarrow$ já tem cinco dia, já pode. eu era assim, né $\downarrow=-$ aí \\
\hline 76 & & depois quando me levaram pra minha casa(0.3), os pessoal, os \\
\hline 77 & & colega meu, “cadê ele $\uparrow$ tá aí?” “tá aí.” aí, quando:: cheguei \\
\hline 78 & & assim $\downarrow$ me chamavam e eu não sabia $\downarrow($.$) e eu só: só fazia$ \\
\hline 79 & & assim, ((balançando a cabeça negativamente))não sabia quem é. \\
\hline
\end{tabular}

Na linha 51, o enunciado de Lívia busca sintomas na fala de Clóvis, solicitando informações adicionais e, ao mesmo tempo, provocando uma quebra da linearidade da narrativa. Nesse momento, Lívia abandona o footing de conarradora e se alinha como terapeuta em um processo de investigação. No turno seguinte, Clóvis, que até então não havia tornado sua fala afásica relevante em sua narração, ao

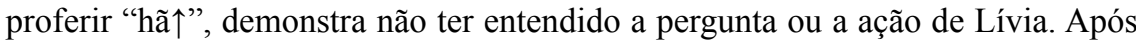
ela (Lívia) reformular sua pergunta na linha 53 (o senhor estava falando ainda?), Clóvis apresenta uma breve explicação e recupera a linearidade da narrativa, sustentando-se no footing de narrador e dando continuidade à narração. Dessa vez, então, foi Clóvis que não quis abandonar tal footing, o que sinaliza que o novo final da história estava por ser construído. Esse movimento de Clóvis mostra que, mesmo com a presença da terapeuta, ele se posiciona como um participante ativo engajado na interação, cujos rumos também cabem ser por ele decididos, o que torna evidente que a configuração do arranjo interacional é um empreendimento coconstruído no aqui e agora da interação, ao invés de imposto e delimitado por assimetrias interacionais de poder vigentes em contextos institucionais.

Torna-se relevante destacar que a conarradora concedeu espaço a Clóvis para ele continuar a narrar ao ratificar os footings por ele estabelecidos na última troca de turnos. Clóvis, então, deu continuidade à narração nas linhas 56-68 com as 
seguintes orações narrativas: ON. 34: pegaram o carro; ON. 35: a gente foi lá no nestor piva; ON. 36: o rapaz chegou; ON. 37: olhou; ON. 38: disse, "ele tem que ficar ao menos uns cinco dias lá no nestor piva"; ON. 39: passei lá; ON. 40: passou um dia, dois dias.; ON. 41: ele "diga seu nome"; ON. 42: "meu nome $\downarrow$ clóvis."; ON. 43: parou. parou.). Após proferir "parou. parou.”, com descida de entonação, Clóvis finalizou a narração; porém, Lívia, no turno seguinte, linha 69, realiza uma pergunta que solicita esclarecimentos acerca da duração do episódio de AVE (isso foi nesses cinco dias que o senhor ficou lá?). Por outro lado, devido ao fato de a ação se caracterizar como uma pergunta, a ação seguinte, da parte de Clóvis, poderia se configurar apenas como uma resposta, e não como uma continuidade à narração, como aconteceu. Clóvis, assim como fez anteriormente, respondeu à pergunta de Lívia e prosseguiu com a narração, apresentando novas orações narrativas (ON. 43: o médico lá, “já coisou já tem cinco dia, já pode.; ON. 44: me levaram pra minha casa, os pessoal.; ON. 45: os colega meu, cadê ele?; ON. 46: “tá aí"). Após essas orações, Clóvis finalizou sua narrativa com avaliações que apontam para o ponto de sua narrativa: o episódio de AVE foi uma longa trajetória de idas e voltas dos hospitais e o deixou sem conseguir falar e sem reconhecer as pessoas.

Cabe ressaltar que a construção do final da narrativa pode ter sido influenciada/ moldada/formatada pela pergunta que Lívia realizou na linha 51, o que corrobora a tese de que narrativas são coconstruções de narradores primários e conarradores. Lívia perguntou como estava a fala de Clóvis e ele finalizou sua narrativa falando da sua fala, tópico que foi introduzido por Lívia. O desenho que as narrativas assumem sofre influência das contribuições (inputs, nos termos de OCHS; CAPPS, 2001) dos conarradores ao longo da interação (OLIVEIRA, 2013).

Uma vez que, com base no modelo interacional de comunicação, tanto falante como ouvinte têm responsabilidade na construção do sentido, não sendo este de responsabilidade apenas do falante, podemos finalizar sumarizando e assumindo que Clóvis, em colaboração com Lívia, construiu uma narrativa coerente em que sentidos foram efetivamente coconstruídos e entendimentos foram partilhados, sendo a intersubjetividade sustentada ao longo da interação. 


\section{Considerações finais}

Sendo o nosso objetivo a investigação das ações do terapeuta na interação com o afásico durante a narração de uma história, é mister destacar que as ações realizadas por Lívia (terapeuta) ao longo da narração - eliciação da narrativa, solicitação de esclarecimento, solicitação de informação adicional, especulação, sinalização de acompanhamento, solicitação de entendimento, pergunta - se configuram como ações de caráter colaborador/cooperador e incentivador/motivador, e abrem espaço para o paciente se engajar ativa e espontaneamente na narração de sua história. Ao solicitar informações adicionais e sinalizar acompanhamento da narração, a terapeuta mostra interesse pela história do paciente, que, por seu turno, busca responder, informar e esclarecer a terapeuta com detalhes que enriquecem a narração e atuam na construção do seu ponto. As produções espontâneas do paciente, do modo como foram evocadas, constituíram um riquíssimo material linguístico para avaliação da linguagem, e as ações da terapeuta podem servir de exemplo de como eliciar produções espontâneas e por meio delas conhecer as possibilidades e potencialidades dos pacientes afásicos.

Ademais, ao solicitar clarificação e ao sinalizar a ausência de ponto na história do paciente, a terapeuta colabora na construção de uma narrativa que cumpra com o critério de coerência e que tenha razão de ser. Por meio dessas ações, foi possível sustentar a intersubjetividade até o final da história.

Houve, ao longo da narração, um interjogo de negociações de footings, em que, em alguns momentos, o paciente quis finalizar a história e a terapeuta propôs a continuidade ao não ratificar a mudança de footing projetada pelo discurso do paciente, e, em outro momento, a terapeuta almejou finalizar a história e o paciente não autorizou tal finalização. Tais negociações resultaram na manutenção dos footings de narrador primário e conarrador até o final da interação, além de tornarem a interação o mais simétrica possível.

Podemos concluir que uma atuação, da parte do terapeuta de linguagem/ fonoaudiólogo, que assume um caráter motivador e incentivador, que dá espaço ao paciente para contar sua história, maximizando seus turnos (alocando para ele a posse da palavra) e mostrando interesse pela história, bem como autorizando o paciente a conduzir a interação, a ter autonomia nas negociações em curso, dissolvendo ao máximo possíveis assimetrias interacionais fruto dos papéis institucionais ali presentes (terapeuta versus paciente), estimula o engajamento ativo do paciente 
na interação, o que propicia espontaneidade no uso contextualizado da linguagem. Apenas essas produções discursivas espontâneas possibilitam ao fonoaudiólogo de fato conhecer a linguagem afetada do sujeito afásico, objeto de sua intervenção. Para intervir eficientemente na (e sobre a) linguagem, é necessário conhecê-la ao máximo, afinal, não há como adentrar um território exótico sem informações que mapeiam nosso trajeto e com isso garantem a chegada ao destino final.

\begin{abstract}
This study is enlightened by the theoretical and methodological framework of the Interactional Sociolinguistics and aims to investigate the interlocutortherapist participation in the construction of an aphasic patient stroke story by looking at the interlocutor's actions that penetrate the turn to turn of the narrative. The analyzed data were video-generated, using the in-depth interview method, and transcribed in accordance with the conversation analysts' stipulations with some adaptations by authors from the interaction field. Qualitative analyses of interpretative nature allowed observing that the therapist's actions contributed to the narrative design/formatting, to the support of the operating footings in the ongoing interaction and to the maintenance of inter-subjectivity. Such actions were cooperative and motivating, and enabled the patient active engagement in the narrative.
\end{abstract}

Keywords: Interaction. Narrative. Aphasia.

\title{
Referências
}

BASTOS, Liliana Cabral. Contando estórias em contextos espontâneos e institucionais: uma introdução ao estudo da narrativa. Calidoscópio, v. 3, n. 2, p. 74-87, 2005.

BASTOS, Liliana Cabral. Narrativa e vida cotidiana. Scripta, Belo Horizonte, v. 14, n. 7, p. 118-127, 2004.

BRITTEN, Nicky. Entrevistas qualitativas. In: POPE, Catherine; MAYS, Nicholas. Pesquisa qualitativa na atenção à saúde. 3. ed. Porto Alegre: Artmed, 2006.

CARRASCO, Maria do Carmo Oliveira. Anamnese ou entrevista: desfazendo equívocos na clínica fonoaudiológica. Dissertação (Mestrado em Distúrbios da Comunicação) - Pontifícia Universidade Católica de São Paulo, São Paulo, 1999.

DURANTI, Alessandro. The audience as co-author: an introduction. Text, v. 6, n. 3, p. 239-247, 1986. 
COUDRY, Maria Irma Hadler. Neurolingüística discursiva: afasia como tradução. Estudos da Linguagem, v. 6, n. 2, p. 7-36, 2008.

GOFFMAN, Erving. Footing. In: RIBEIRO, Branca Telles; GARCEZ, Pedro M. (Org.). Sociolingüística Interacional. São Paulo: Edições Loyola, 2002. p. 107148. Original publicado em 1979.

GOLDSTEIN, Kurt. Language and Language Disturbances. New York: Grune and Stratton, 1948.

GOLDSTEIN, Kurt. The Organism: a Holistic Approach to Biology Derived from Pathological Data in Man. New York: Zone Books, 1939.

GOODWIN, Charles. Audience diversity, participation and interpretation. Text, v. 6, n. 3, p. 283-316, 1986.

GOODWIN, Charles. Co-constructing Meaning in Conversations with an Aphasic Man. Research on Language and Social Interaction, v. 28, p. 233-60, 1995.

GAVRUSEVA, Lena. Positioning and Framing: constructing interactional asymmetry in employer-employee discourse. Discourse Processes, v. 20, p. 325345, 1995.

HEESCHEN, Claus; SCHEGLOFF, Emanuel A. Aphasic agrammatism as interactional artifact and achievement. In: Goodwin, Charles (Org.). Conversation and brain damage. New York: Oxford University Press, 2003. p. 231-282.

HEESCHEN, Claus; SCHEGLOFF, Emanuel A. Agrammatism, adaptation theory, conversation analysis: on the role of so-called telegraphic style in talk-ininteraction. Afasiology, v. 13, n. 4/5, p. 365-405, 1999.

JACKSON, John Hughlings. Selected Writings of John Hughlings Jackson. In: TAYLOR, James (Ed.). London: Hodder and Staughton, 1931.

JACOBY, Sally; OCHS, Elinor. Co-construction: an introduction. Research on Language and Social Interaction, (Special Issue). v. 28, n. 3, p. 171-183, 1995.

LABOV, William. The transformation of experience in narrative syntax. In: LABOV, William. Language in the inner city. Philadelphia: University of Philadelphia Press, 1972. p. 354-396.

LABOV, William; WALETZKY, Joshua. Narrative Analysis: oral versions of personal experience. In: HELM, June. Essays on the verbal and visual arts. Seattle: University of Washington Press, 1967. p. 12-44. 
LANINI, Aline Gruppi; OLIVEIRA, Mônika Miranda de: VIEIRA, Amitza Torres. A utilização da prosódia por uma pessoa com afasia como um recurso para lidar com o déficit linguístico. Revista Gatilho, v. 10, n. 1, p. 1-21, 2010.

MISHLER, Elliot. Storylines: craftartists' narratives of identity. Cambridge: Harvard University Press, 1999. 180 p.

NORRICK, Neal R. Conversational storytelling. In.: HERMAN, David (Ed.). The Cambridge companion to narrative. Cambridge: Cambridge University Press, 2007. p. 127-141.

OCHS, Elinor; CAPPS, Lisa. Living Narrative: Creating Lives in Everyday Storytelling. Harvard: Harvard University Press, 2001. 352 p.

OLIVEIRA, Livia Miranda de. A performance de pessoas com afasia na construção de narrativas em interações face a face em grupo. 2013. $170 \mathrm{f}$. Tese (Doutorado em Estudos da Linguagem) - Departamento de Letras, Pontifícia Universidade Católica do Rio de Janeiro, 2013.

OLIVEIRA, Livia Miranda de; BASTOS, Liliana Cabral. Aspectos da dinâmica interacional da narração de histórias por pessoas com afasia. Calidoscópio, v. 10, p. 194-210, 2012.

OLIVEIRA, Livia Miranda de; BASTOS, Liliana Cabral. Uma história de AVC: a construção do sofrimento por uma pessoa com afasia. Veredas - Revista de Estudos Linguísticos, v. 15, n. 1, p. 120-135, 2011.

OLIVEIRA, Livia Miranda de; OLIVEIRA, Mônika Miranda de. O uso do discurso reportado direto por uma pessoa com afasia na construção de uma narrativa. Revista CEFAC, v. 16, p. 131-146, 2014.

PACHECO, Mirian Cazarotti; PINTO, Rosana do Carmo Novaes. Aspectos Discursivos da Narrativa de um Sujeito Afásico Fluente. Estudos Linguísticos, v. 39 , n. 2 , p. $568-577,2010$.

PENN, Claire. Compensation and language recovery in the chronic aphasic patient. Aphasiology, v. 1, p. 235-245, 1987.

RIBEIRO, Branca Telles; GARCEZ, Pedro M. Sociolingüística Interacional. São Paulo, Edições Loyola, 2002. 271 p.

RIESSMAN, Catherine Kohler. Narrative Methods for the Human Sciences. California: Sage Publication, 2008. 251 p. 
SACKS, Harvey, Lecture 1. Second stories; 'Mm hm;" Story prefaces; 'Local news;'. Tellability. In Lectures on conversation. Oxford: Basil Blackwell, 1992. Original publicado em 1968. v. 1.

SACKS, Harvey, Lecture 2. Features of a recognizable 'story;' Story prefaces; Sequential locator terms; Lawful interruption. In Lectures on conversation. Oxford, Basil Blackwell, 1992. v. 1. Original publicado em 1968.

SACKS, Harvey; SCHEGLOFF, Emanuel A.; JEFFERSON, Gail. Sistemática elementar para a organização da tomada de turnos para a conversa. Revista Veredas de Estudos Lingüísticos, v. 7, n. 12, p. 1-67, 2005. Tradução de $A$ Simplest Systematics for the Organization of Turn Taking for Conversation. Language, publicado em 1974.

SCHIFFRIN, Deborah. Interactional Sociolinguistics. In: SCHIFFRIN, Deborah. Approaches to discourse. Cambridge, MA; Oxford: Blackwell, 1994. p. 97-136, cap. 4.

SCHIFFRIN, Deborah. Discourse and Communication. In: SCHIFFRIN, Deborah. Approaches to discourse. Cambridge, MA; Oxford: Blackwell, 1994. p. 386405, cap. 11.

SCHIFFRIN, Deborah. How a story says what it means and does? Text, v. 4, n. 4, p. 313-346, 1984.

TANNEN, Deborah. "On Talking voice that is so sweet": constructing dialogue in conversation. In: TANNEN, Deborah. Talking voices: repetition, dialogue and imagery in conversational discourse. Cambridge: Cambridge University Press, 1989. p. 98-133.

WILKINSON, Ray; BEEKE, Suzanne; MAXIM, Jane. Formulating Actions and Events with Limited Linguistic Resources: Enactment and Iconicity in Agrammatic Aphasic Talk. Research on Language \& Social Interaction, v. 43, n. 1, p. 57-84, 2010.

WILKINSON, Ray; GOWER, Morweena; BEEKE, Suzanne; MAXIM, Jane. Adapting to conversation as a language-impaired speaker: Changes in aphasic turn construction over time. Comunication \& Medicine: An Interdisciplinay Journal of Healthcare, Ethics \& Society, v. 4, n. 1, p. 79-98, 2007. 
Anexo

Convenções de Transcrição

\begin{tabular}{|ll|}
\hline$[$ colchetes] & fala sobreposta \\
$()$. & micropausa \\
$=$ & contiguidade entre a fala de um mesmo falante ou de dois falantes distintos \\
descida de entonação \\
$?$ & subida de entonação \\
$\vdots$ & entonação contínua \\
- & alongamento de som \\
Sublinhado & auto-interrupcão \\
MAIÚSCULA & acento ou ênfase de volume \\
$\uparrow$ & subida acentuada \\
$\downarrow$ & descida acentuada na entonação \\
$>$ palavras $<$ & fala comprimida ou acelerada \\
$<$ palavras $>$ & desaceleração da fala \\
$(())$ & comentários do analista \\
$($ palavras $)$ & transcrição duvidosa \\
$($ ) & transcrição impossível \\
$\ldots$ & pausa não medida \\
“palavra" & fala reportada, reconstrução de um diálogo \\
\hline
\end{tabular}

Submetido em: 09 de julho de 2015. Aceito para publicação em: 26 de novembro de 2015. 